\title{
Effectiveness of preemptive antifibrinolysis with tranexamic acid in rheumatoid arthritis patients undergoing total knee arthroplasty: a study protocol for a randomized controlled trial
}

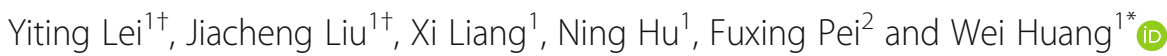

\begin{abstract}
Background: Patients with rheumatoid arthritis (RA) who have undergone total knee arthroplasty are at increased risk of requiring a blood transfusion. This study is designed to compare the effects of preemptive antifibrinolysis of single-dose and repeat-dose tranexamic acid (TXA) in in RA patients undergoing total knee arthroplasty (TKA).

Methods/design: The study will be a double-blind randomized controlled trial with two parallel groups of RA patients. Group A will be given $100 \mathrm{ml}$ normal saline twice daily starting from 3 days before the operation, Group B will be given TXA $1.5 \mathrm{~g}$ twice daily starting from 3 days before the operation. All patients will be given TXA $1.5 \mathrm{~g} 30$ min before the operation. The primary outcomes will be evaluated with total blood loss and hidden blood loss. Other outcome measurements such as, fibrinolysis parameters, inflammatory factors, visual analogue scale for postoperative pain, analgesia usage, coagulation parameters, transfusion, the length of stay (LOS), total hospitalization costs, the incidence of thromboembolic events and other complications will be recorded and compared. Recruitment is scheduled to begin on 1 August 2020, and the study will continue until 31 May 2021.

Discussion: In current literature there is a lack of evidence with regard to the efficacy of TXA in RA patients. The findings of this study, whether positive or negative, will contribute to the formulation of further recommendations on the use of TXA in RA patients undergoing TKA.
\end{abstract}

Trial registration: Chinese Clinical Trial Registry, ChiCTR2000029720. Registered 14 February 2020.

Keywords: Tranexamic acid, Total knee arthroplasty, Rheumatoid arthritis, Preemptive antifibrinolysis

\footnotetext{
* Correspondence: huangw511@163.com

${ }^{\dagger}$ Yiting Lei and Jiacheng Liu contributed equally to this work.

'Department of Orthopedics, The First Affiliated Hospital of Chongqing Medical University, Chongqing 400016, China

Full list of author information is available at the end of the article
}

(c) The Author(s). 2020 Open Access This article is licensed under a Creative Commons Attribution 4.0 International License, which permits use, sharing, adaptation, distribution and reproduction in any medium or format, as long as you give appropriate credit to the original author(s) and the source, provide a link to the Creative Commons licence, and indicate if changes were made. The images or other third party material in this article are included in the article's Creative Commons licence, unless indicated otherwise in a credit line to the material. If material is not included in the article's Creative Commons licence and your intended use is not permitted by statutory regulation or exceeds the permitted use, you will need to obtain permission directly from the copyright holder. To view a copy of this licence, visit http://creativecommons.org/licenses/by/4.0/ The Creative Commons Public Domain Dedication waiver (http://creativecommons.org/publicdomain/zero/1.0/) applies to the data made available in this article, unless otherwise stated in a credit line to the data. 


\section{Background}

As the one of the most common inflammatory arthritis affecting about $1 \%$ of world population $[1,2]$, rheumatoid arthritis (RA) is associated with an increasing socioeconomic impact and often affects the diarthrodial joints, including knee joint [3, 4]. Total knee arthroplasty (TKA) is considered one of the most effective orthopedic health care interventions for patients with rheumatoid arthritis (RA) [5-8], and RA patients achieve better satisfaction after TKA compared to patients with osteoarthritis (OA) [8]. However, fibrinolysis stimulated by surgical trauma could lead to significant blood loss $[9,10]$, and RA patients undergoing this procedure tend to have a higher risk of requiring transfusion than $\mathrm{OA}$ patients, owing to preoperative anemia, lower average weight, great bone mass loss, complete synovectomy and extensive soft tissue separation $[11,12]$. Blood transfusion is often associated with infectious or noninfectious complications [13], and can prolonged hospital stays, delay recovery and increase medical expenses [14]. Therefore, decreasing blood loss, which can subsequently reduce the requirement for transfusion, is extremely important for patient to improve the quality of life.

As an antifibrinolytic agent, the hemostatic effect of tranexamic acid (TXA) has been proven in TKA $[9,10$, 15]. However, in view of the fact that almost $97 \%$ of TKAs are performed for OA [16], current published studies in terms of the efficacy of TXA were mainly based on the experience in OA patients $[9,17-20]$, and there still exists a paucity of evidence with regard to the efficacy of TXA in RA patients. Unlike OA, RA has its own features in the aspects of pathogenesis, prognosis, and medical management [5]. It has been reported that RA patients had higher preoperative D-dimer value than OA patients [21]. Therefore, TXA is theoretically more suitable for RA patients compared to OA patients, and a specially designed TXA scheme for RA patients with TKA is urgently needed.

The most common preoperative protocol of TXA in TKA is to administer one single dose prior to skin incision [9, 22-24], which might seem to be insufficient to inhibit fibrinolysis in RA patients. Therefore, we plan to conduct a randomized clinical trial to compare the effects of preemptive antifibrinolysis of single-dose and repeat-dose TXA in RA patients undergoing TKA.

\section{Methods}

\section{Study design}

The study will be a randomized, prospective, doubleblind (patient and evaluator) clinical trial. This study has been approved, and conforms to the Declaration of Helsinki. The trial has been registered at the Chinese Clinical Trial Registry (ChiCTR2000029798). Informed consent will be obtained. The schedule of trial enrolment and assessments is shown in Table 1. The trial flow chart is shown in Fig. 1.

\section{Randomization and blinding}

Patients will be randomized into two groups at 1:1 ratio. Randomization will be done based on a computergenerated allocation sequence with random block sizes of 2,4 , and 6 , which was stratified by methotrexate use at baseline $(0 \mathrm{mg} /$ week, $>0$ to $<12.5 \mathrm{mg} /$ week, or $\geq 12.5$ $\mathrm{mg} /$ week) [25]. Group data will be placed into opaque sealed envelopes. Only nurse and anesthetist who are not involved in this trial will be allowed to check the enrollment and give the corresponding treatment. The outcome evaluators will objectively record the patients' test results. The surgical team, the study investigators, and the patient will be blinded to interventions until the final data analysis.

\section{Inclusion criteria}

(1) The patient is diagnosed with RA in Stage III or IV according to the Kellgren-Lawrence classification [26];

(2) The patient will sign informed consent;

(3) The patient will undergo the unilateral primary TKA.

\section{Exclusion criteria}

(1) A history of a thromboembolic event;

(2) Received anticoagulant therapy (warfarin or heparin) within the previous week;

(3) Cardiovascular problems or cerebrovascular conditions (history of myocardial infarction, angina, atrial fibrillation, or previous stroke);

(4) An acquired or congenital coagulopathy;

(5) Allergy to TXA.

\section{Termination criteria}

The patient will be terminated under the following conditions: (1) Shock; (2) Seizure; (3) Digestive disorders, such as nausea, vomiting and diarrhea after administration; (4) Embolic events, such as pulmonary embolism.

\section{Perioperative anti-rheumatic treatment}

Nonbiologic disease-modifying antirheumatic drugs (DMARDs) such as methotrexate, hydroxychloroquine, leflunomide, and/or sulfasalazine, will be used throughout the perioperative period. Biologic agents will be withheld prior to TKA and surgery will be planned at the end of the dosing cycle for that specific medication. The biologic therapy will be restarted when the wound shows evidence of healing without surgical site infections (typically two weeks after TKA) [27].

\section{Surgery and anesthesia}

All the operations will be performed by 2 surgical team composed of 3 senior surgeons (WH, XL and $\mathrm{NH}$ ) under 
Table 1 The schedule of trial enrolment and assessments

\begin{tabular}{|c|c|c|c|c|c|c|c|c|c|}
\hline & \multicolumn{9}{|c|}{ Study period } \\
\hline & Pre-D3 & Pre-D1 & $\mathrm{OP}$ & D1 & D2 & D3 & DOD & D14 & D90 \\
\hline \multicolumn{10}{|l|}{ Enrolment } \\
\hline Eligibility screen & $\bullet$ & & & & & & & & \\
\hline Informed consent & $\bullet$ & & & & & & & & \\
\hline Randomization & $\bullet$ & & & & & & & & \\
\hline \multicolumn{10}{|l|}{ Outcome assessment } \\
\hline TBL & & & & $\bullet$ & $\bullet$ & $\bullet$ & & & \\
\hline $\mathrm{IBL}$ & & & $\bullet$ & & & & & & \\
\hline $\mathrm{HBL}$ & & & & $\bullet$ & $\bullet$ & $\bullet$ & & & \\
\hline Hemoglobin level & $\bullet$ & $\bullet$ & & $\bullet$ & $\bullet$ & $\bullet$ & & $\bullet$ & \\
\hline Fibrinolysis parameters & $\bullet$ & $\bullet$ & & $\bullet$ & $\bullet$ & $\bullet$ & & $\bullet$ & \\
\hline Inflammatory markers & $\bullet$ & $\bullet$ & & $\bullet$ & $\bullet$ & $\bullet$ & & $\bullet$ & \\
\hline Coagulation parameters & $\bullet$ & $\bullet$ & & $\bullet$ & $\bullet$ & $\bullet$ & & $\bullet$ & \\
\hline Pain level & $\bullet$ & $\bullet$ & & $\bullet$ & $\bullet$ & $\bullet$ & & $\bullet$ & \\
\hline Analgesia usage & & & & $\bullet$ & $\bullet$ & $\bullet$ & & & \\
\hline Knee range of motion & $\bullet$ & $\bullet$ & & $\bullet$ & $\bullet$ & $\bullet$ & & $\bullet$ & $\bullet$ \\
\hline LOS & & & & & & $\bullet$ & & & \\
\hline Hospitalization costs & & & & & & $\bullet$ & & & \\
\hline DVT & & & & & & $\bullet$ & & $\bullet$ & $\bullet$ \\
\hline PE & & & & & & $\bullet$ & & $\bullet$ & $\bullet$ \\
\hline Adverse events & & & & $\bullet$ & $\bullet$ & $\bullet$ & $\bullet$ & $\bullet$ & $\bullet$ \\
\hline
\end{tabular}

Pre-D3, 3 days before surgery; Pre-D1, 1 day before surgery; OP, operative; TBL, total blood loss; IBL, intraoperative blood loss; HBL, hidden blood loss; LOS, length of stay; DVP, deep vein thrombosis; PE, pulmonary embolism; D1, the 1st day after surgery; D2, the 2nd day after surgery; D3, the 3rd day after surgery; DOD, the day of discharge; D14, the 14th day after surgery; D90, the 90th day after surgery

general anesthesia. The operations will be done in the standard way, with a midline skin incision, a standard medial parapatellar approach, and a measured resection technique. The tourniquet will be applied throughout the whole procedure and will not be released until skin closure. A drainage catheter will be used in every patient for at least $24 \mathrm{~h}$, and will be removed according to the volume of drainage.

\section{Study interventions}

Group A: $100 \mathrm{~mL}$ normal saline (NS) will be administrated intravenously twice daily starting from 3 days before the operation (performed by a nurse). $1.5 \mathrm{~g}$ of TXA will be given 30 min before the operation (performed by an anesthetist).

Group B: $1.5 \mathrm{~g}$ of TXA will be given twice daily starting from 3 days before the operation (performed by a nurse). $1.5 \mathrm{~g}$ of TXA will be given $30 \mathrm{~min}$ before the operation (performed by an anesthetist).

TXA is produced by Chongqing Lummy Pharmaceutical Co., Ltd., and used according to the second edition of 2015 Chinese Pharmacopoeia and Drug Supplement
Application Approval YBH19712005; the approval number is National Drug Standard H20056600.

\section{Antibiotics}

$1.5 \mathrm{~g}$ of cefuroxime sodium will be given $30 \mathrm{~min}$ preoperatively and every $12 \mathrm{~h}$ for 6 times by intravenous drip after the TKA

\section{Pain management and rehabilitation}

The strategies to alleviate pain for all patients will be the same. Intravenous or oral NSAIDs combined with patients-controlled intravenous analgesia (PCIA) will be used after TKA for analgesia. Daily function training (active range of motion training, strength training, and walking training) will be followed out under the supervision and assistance of a physiotherapist.

\section{Venous thromboembolism prophylaxis}

All patients will receive the same routine chemical thromboprophylaxis after operation. Patients will receive $10 \mathrm{mg}$ Rivaroxaban (Xarelto, Bayer, Germany) $12 \mathrm{~h}$ postoperatively, repeating at 24-h intervals for 14 days. 


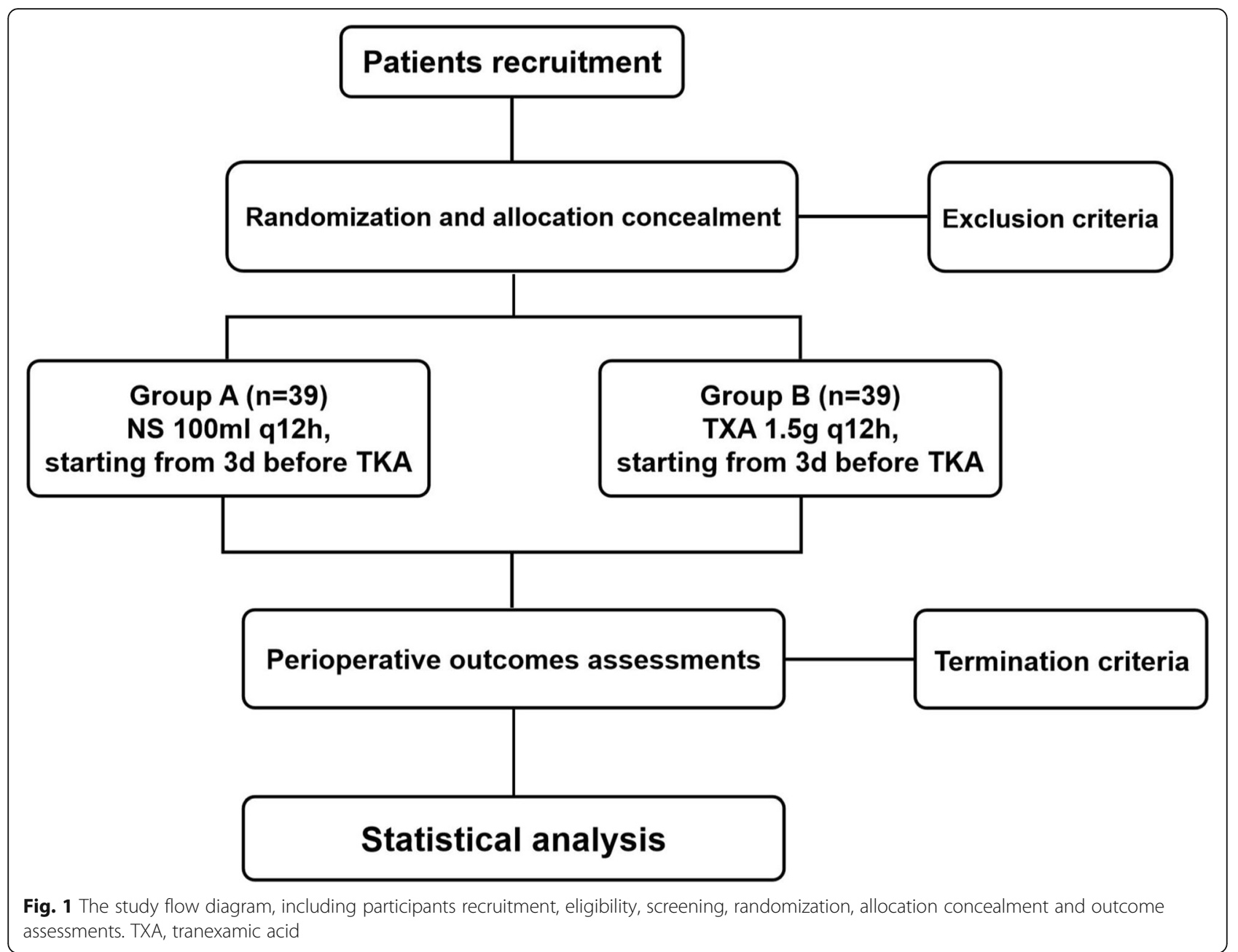

\section{Primary outcomes}

Perioperative blood loss

The patient's blood volume (PBV) and perioperative blood loss are calculated according to Nadle et al. [28] and Gross formula [29]:

The patient's blood volume $(\mathrm{PBV})[28]=\mathrm{k} 1 \times$ height $(\mathrm{m})+\mathrm{k} 2 \times$ weight $\quad(\mathrm{kg})+\mathrm{k} 3 \quad$ (male: $\mathrm{k} 1=0.3669, \quad \mathrm{k} 2=$ 0.03219 , $\mathrm{k} 3=0.6041$; female: $\mathrm{k} 1=0.3561, \mathrm{k} 2=0.03308$, $\mathrm{k} 3=0.1833$ for women).

The total blood loss (TBL) [29] = PBV $\times\left(\right.$ Hct $_{\text {pre }}-$ Hct $\left._{\text {post }}\right) /$ Hct $_{\text {ave }}\left(\right.$ Hct $_{\text {pre }}=$ preoperative hematocrit level. Hct $_{\text {post }}=$ the lowest postoperative hematocrit level during hospitalization. $\mathrm{Hct}_{\mathrm{ave}}=$ the average of the Hct $\mathrm{pre}_{\text {pe }}$ act $\left.\mathrm{post}_{\mathrm{p}}\right)$.

The intraoperative blood loss (IBL) [30] = (the weight of the gauze pads and compresses with blood - the dry weight of the gauze pads and compresses) + (the volume collected by the aspirators - the volume used to wash the surgical area).

The hidden blood loss (HBL) [31] = TBL - measured blood loss (measured blood loss mainly included IBL and the volume of drainage).

\section{Secondary outcomes}

Fibrinolysis parameters, inflammatory markers and coagulation parameters

Fibrinolysis parameters [fibrin(-ogen) degradation products (FDP), D-dimer], inflammatory markers [erythrocyte sedimentation rate (ESR), C-reactive protein (CRP), interleukin-6 (IL-6)] and coagulation parameters [activated partial thromboplastin time (APTT), prothrombin time (PT) and thrombelastography (TEG)] will be tested 1 and 3 days before surgery and 1, 2, 3 and 14 days after surgery. All measurements will be performed by the Department of Clinical Laboratory of The First Affiliated Hospital of Chongqing Medical University.

\section{Post-operative pain score and analgesia usage}

Pain level at rest (rest in bed at least for $30 \mathrm{~min}$ before test) and during activity (from sitting to standing position) will be assessed using a visual analogue scale ( 0 means no pain, 10 means severe pain imaginable) and will be conducted 1 and 3 days before surgery and 1, 2, 3 
and 14 days after surgery, and the analgesia usage will be carefully recorded.

\section{Transfusion and knee function}

Transfusion will be carefully recorded during hospitalization and follow-up period. The criterion of blood transfusion in our medical institution will be in accordance with the guidelines of the National Ministry of Health [9]: (1) the hemoglobin ( $\mathrm{Hb})$ level is equal to or less than $70 \mathrm{~g} / \mathrm{L}$; (2) the $\mathrm{Hb}$ level is between $70 \mathrm{~g} / \mathrm{L}$ and $100 \mathrm{~g} / \mathrm{L}$, with intolerable symptom of anemia (dizziness, tachycardia, tachypnea, or decreased exercise tolerance).

The knee range of motion will be measured preoperatively and 1,2,3,14 and 90 days after TKA, and the knee angle will be measured by goniometer.

\section{Length of stay and total hospitalization costs}

The LOS will be recorded from the day of admission to discharge. Total hospitalization cost will be defined as the total payment that the patients' primary insurance carrier provides to the hospital.

\section{Adverse events}

Each patient will be screened with clinical symptoms (acute onset, swelling, sever pain) and physical examination (significant tenderness at the femoral triangle or/ and leg) to ensure no deep vein thrombosis (DVT) is present. Doppler ultrasound in diagnosis of venous thrombosis of lower extremities will be performed at the time of hospital discharge, and repeated at 2 weeks and 3 months after TKA.

Pulmonary embolism (PE) will be investigated by clinical signs and symptoms (cough, hemoptysis, chest tightness, tachypnea, shock, dizziness, cyanosis, etc.). Patient with clinically suspected PE will undergo a contrast-enhanced chest CT scan immediately.

The wound complications (ecchymosis, bleeding, local hematoma, superficial and deep infection) will be carefully recorded during hospitalization and follow-up period.

\section{Data management}

Each participant's identification number and baseline data will be electronically contained in CRFs. Outcome data will be put in the CRF by two independent trained research assistants with a double-entry method. No personal data will be shared with any other outside party.

\section{Sample size calculation}

Sample size was estimated based on a large database generated from a prospective multicenter study sponsored by the Chinese Health Ministry (project number 201302007) using PASS 2011 (NCSS, LLC. Kaysville, Utah, USA) software. According to the database, the
TBL was $730.96 \pm 262.85 \mathrm{~mL}$, with a single dose of TXA before TKA in RA patients. To detect a difference of $200 \mathrm{~mL}$ of primary end point, with a power of 0.90 and the significance level of $0.05,31$ patients per arm will be needed. Considering a dropout rate of $20 \%$, we decided to involve 39 patients in each arm.

\section{Statistical analysis}

Statistical analyses will be performed using SPSS version 24 (SPSS Inc. USA) software. We will use the independent samples t-test (Student's t-test) to evaluate quantitative data with normal distribution, and use Mann-Whitney U-test for data not having normal distribution. Pearson Chi-square test or Fisher exact test will be used to analyze qualitative comparative data. $P$ values will be judged significant if they are less than 0.05 .

\section{Ethics and dissemination}

This clinical trial has been approved by the ethics committee of the First Affiliated Hospital of Chongqing Medical University (2019-015). The data will be published on the website of the China Clinical Trials Registry and the results of this study will be published in a peer-reviewed journal in accordance with CONSORT, and disseminated at relevant national and international conferences.

\section{Discussion}

To our best knowledge, this will be one of the first attempt to compare the effects of preemptive antifibrinolysis of single-dose and repeat-dose TXA in RA patients undergoing TKA. The hemostatic effect of TXA has been well-established in OA patients undergoing TKA [9, 10, 32]. However, the efficacy and safety of TXA in RA patients is still undetermined. Compared with OA patients, RA patients are at a higher risk of requiring blood transfusion [11, 12]. Mukubo et al. found that D-dimer in RA patients was ten times normal, indicating a hyperfibrinolytic state in RA patients prior to surgery [21]. In addition, fibrinolysis can also be caused by surgical trauma and enhanced by tourniquet [9]. Since fibrinolytic activation is a cascade process and is most easily inhibited at its early stage [33], the preoperative dose has been deemed as the most significant dose $[23,34]$. Hourlier et al. indicated that the reason why the previous studies failed to show the efficacy of singledose treatment may owe to the lack of dosage [35]. Therefore, we assume that repeat-dose preoperative TXA may exert an auxiliary antifibrinolytic effect. In this trial, different preoperative dosing regimen will be compared, which will contribute to the formulation of further recommendations on the use of TXA for reducing blood loss in RA patients undergoing TKA. 
RA is characterized by persistent synovitis and systemic inflammation, which may lead to joint deformity and disability [36, 37]. In addition, since inflammation and atherosclerosis are closely linked, it is reported that satisfactory inflammation control is likely to decrease the cardiovascular risk in patients with RA [38]. Despite numerous studies proving the effect of TXA on fibrinolysis, it still remains unclear in terms of its antiinflammatory properties $[9,17,39]$. Data from previous studies showed that D-dimer could stimulate monocytes to synthesize and release IL-6, indicating that there is a close connection between fibrinolysis and inflammation [40, 41]. Jimenez et al. found that double-dose TXA could prolong the inhibition of fibrinolysis and alleviate postoperative inflammation in cardiopulmonary bypass (CPB) patients [42]. However, evidence is scarce in RA patients with regard to the anti-inflammatory effect of TXA. In this trial, we will compare different preoperative TXA regimens, suspecting that repeat-dose preoperative TXA could provide additional inflammation control.

A number of previous studies have demonstrated the presence of preoperative blood hypercoagulability in RA patients, which is a risk factor of postoperative venous thromboembolism (VTE) [43]. In addition, concerns about the potential pro-coagulation effect of TXA in this high-risk patient population still hinder the wide application of this medication in TKA [44]. Therefore, we plan a prospective randomized controlled study to evaluate the safety of different TXA regimens in RA patients undergoing TKA. In this study, we will use APTT, PT and TEG to detect perioperative blood hypercoagulability in patients with RA, which may provide some insights to assess the safety of TXA in RA patients.

\section{Abbreviations}

RA: Rheumatoid Arthritis; TXA: Tranexamic Acid; TKA: Total Knee Arthroplasty; LOS: Length of Stay; OA: Osteoarthritis; DMARDs: Nonbiologic Diseasemodifying Antirheumatic Drugs; NS: Normal Saline; PCIA: Patients-controlled Intravenous Analgesia; PBV: Patient's Blood Volume; TBL: Total Blood Loss; IBL: Intraoperative Blood Loss; HBL: Hidden Blood Loss; FDP: Fibrin(-ogen) Degradation Products; ESR: Erythrocyte Sedimentation Rate; CRP: C-reactive Protein; IL-6: Interleukin-6; APTT: Activated Partial Thromboplastin Time; PT: Prothrombin Time; TEG: Thrombelastography; Hb: Hemoglobin; DVT: Deep Vein Thrombosis; PE: Pulmonary Embolism; CONSORT: Consolidated Standards of Reporting Trials

\section{Acknowledgments}

The authors thank all the patient advisers for participating in this study.

\section{Study status}

Recruitment is scheduled to begin on 1 August 2020, and the study will continue until 31 May 2021.

\section{Related Articles}

There are not any publications containing the results of this study have already been published or submitted to any journal.

\section{Authors' contributions}

YTL and JCL conceived the study while XL, NH and FXP designed the study. The study protocol was drafted by WH. All authors approved the final manuscript of this study protocol.

\section{Funding}

This study has not received external funding.

Availability of data and materials

Not applicable.

\section{Ethics approval and consent to participate}

The study protocol has been approved by the research ethics committee of the Chongqing Medical University (CQMU) (ethical number: 2019-015) and has been registered at chictr.org.cn with number ChiCTR2000029720 on February 14th, 2020. All subjects will provide written informed consent to participate.

\section{Consent for publication}

All volunteers are aware of this publication and have clarified the importance of the study and publication of the manuscript.

\section{Competing interests}

The authors declare that they have no competing interests.

\section{Author details}

'Department of Orthopedics, The First Affiliated Hospital of Chongqing Medical University, Chongqing 400016, China. ${ }^{2}$ Department of Orthopedics, West China Hospital, Sichuan University, Chengdu 610041, Sichuan, China.

Received: 18 February 2020 Accepted: 7 July 2020

Published online: 15 July 2020

\section{References}

1. Alamanos $Y$, Drosos AA. Epidemiology of adult rheumatoid arthritis. Autoimmun Rev. 2005;4(3):130-6.

2. Tobon GJ, Youinou P, Saraux A. The environment, geo-epidemiology, and autoimmune disease: Rheumatoid arthritis. J Autoimmun. 2010;35(1):10-4.

3. Meng XH, Wang Z, Zhang XN, Xu J, Hu YC. Rheumatoid Arthritis of Knee Joints: MRI-Pathological Correlation. Orthop Surg. 2018;10(3):247-54.

4. Chandrashekara S, Shobha V, Dharmanand BG, Jois R, Kumar S, Mahendranath KM, Haridas V, Prasad S, Singh Y, Daware MA, Swamy A, Subramanian R, Somashekar SA, Shanthappa AM, Anupama KR. Influence of disease duration and socioeconomic factors on the prevalence of infection and hospitalization in rheumatoid arthritis: KRAC study. Int J Rheum Dis. 2019;22(7):1216-25.

5. Ravi B, Escott B, Shah PS, Jenkinson R, Chahal J, Bogoch E, Kreder H, Hawker $\mathrm{G}$. A systematic review and meta-analysis comparing complications following total joint arthroplasty for rheumatoid arthritis versus for osteoarthritis. Arthritis Rheum. 2012;64(12):3839-49.

6. Kumagai K, Harigane K, Kusayama Y, Tezuka T, Inaba Y, Saito T. Total knee arthroplasty improves both knee function and disease activity in patients with rheumatoid arthritis. Mod Rheumatol. 2017;27(5):806-10.

7. Stundner O, Danninger T, Chiu YL, Sun X, Goodman SM, Russell LA, Figgie M, Mazumdar M, Memtsoudis SG. Rheumatoid arthritis vs osteoarthritis in patients receiving total knee arthroplasty: perioperative outcomes. J Arthroplast. 2014;29(2):308-13.

8. Kobayashi S, Niki Y, Harato K, Nagura T, Nakamura M, Matsumoto M. Rheumatoid Arthritis Patients Achieve Better Satisfaction but Lower Functional Activities as Compared to Osteoarthritis Patients After Total Knee Arthroplasty. J Arthroplasty. 2019;34(3):478-82 e1.

9. Xie J, Ma J, Yao H, Yue C, Pei F. Multiple Boluses of Intravenous Tranexamic Acid to Reduce Hidden Blood Loss After Primary Total Knee Arthroplasty Without Tourniquet: A Randomized Clinical Trial. J Arthroplast. 2016;31(11): 2458-64.

10. Lei Y, Xie J, Xu B, Xie X, Huang Q, Pei F. The efficacy and safety of multipledose intravenous tranexamic acid on blood loss following total knee arthroplasty: a randomized controlled trial. Int Orthop. 2017;41(10):2053-9.

11. Li B, Liu ZT, Shen P, Zhou BZ, Bai LH. Comparison of therapeutic effects between drainage blood reinfusion and temporary clamping drainage after total knee arthroplasty in patients with rheumatoid arthritis. Clinics (Sao Paulo). 2015;70(3):202-6.

12. Leino KA, Palve HK, Tiusanen HT, Tuppurainen $\Pi$. The effect of desmopressin on blood loss in patients with rheumatoid arthritis undergoing hip arthroplasty. Acta Anaesthesiol Scand. 2010;54(7):863-70. 
13. Ogbemudia AE, Yee SY, MacPherson GJ, Manson LM, Breusch SJ. Preoperative predictors for allogenic blood transfusion in hip and knee arthroplasty for rheumatoid arthritis. Arch Orthop Trauma Surg. 2013;133(9): 1315-20.

14. Brito SA, Rankin EA, McNear M. Acute Blood Loss Anemia in the Octogenarian Total Knee Arthroplasty, Estimated Blood Loss and Transfusions Rates. J Natl Med Assoc. 2016;108(1):86-9.

15. Huang Z, Ma J, Shen B, Pei F. Combination of intravenous and topical application of tranexamic acid in primary total knee arthroplasty: a prospective randomized controlled trial. J Arthroplast. 2014;29(12): 2342-6.

16. Collins JE, Rome BN, Daigle ME, Lerner V, Katz JN, Losina E. A comparison of patient-reported and measured range of motion in a cohort of total knee arthroplasty patients. J Arthroplasty. 2014;29(7):1378-82 e1.

17. Xie J, Hu Q, Ma J, Huang Q, Pei F. Multiple boluses of intravenous tranexamic acid to reduce hidden blood loss and the inflammatory response following enhanced-recovery primary total hip arthroplasty: a randomised clinical trial. Bone Joint J. 2017;99-b(11):1442-9.

18. Morrison RJM, Tsang B, Fishley W, Harper I, Joseph JC, Reed MR. Dose optimisation of intravenous tranexamic acid for elective hip and knee arthroplasty: The effectiveness of a single pre-operative dose. Bone Joint Res. 2017;6(8):499-505

19. Maniar RN, Kumar G, Singhi T, Nayak RM, Maniar PR. Most effective regimen of tranexamic acid in knee arthroplasty: a prospective randomized controlled study in 240 patients. Clin Orthop Relat Res. 2012;470(9):2605-12.

20. Xie J, Hu Q, Huang Q, Ma J, Lei Y, Pei F. Comparison of intravenous versus topical tranexamic acid in primary total hip and knee arthroplasty: An updated meta-analysis. Thromb Res. 2017;153:28-36.

21. Mukubo Y, Kawamata M. Higher preoperative D-dimer value remain high postoperatively in patients with rheumatoid arthritis compared with those with osteoarthrosis. J Anesth. 2006;20(1):51.

22. Bidolegui F, Arce G, Lugones A, Pereira S, Vindver G. Tranexamic Acid Reduces Blood Loss and Transfusion in Patients Undergoing Total Knee Arthroplasty without Tourniquet: A Prospective Randomized Controlled Trial. Open Orthop J. 2014;8(1):250

23. Jain NP, Nisthane PP, Shah NA. Combined Administration of Systemic and Topical Tranexamic Acid for Total Knee Arthroplasty: Can It Be a Better Regimen and Yet Safe? A Randomized Controlled Trial. J Arthroplasty. 2016; 31(2):542-7.

24. Hogan CA, Golightly LK, Phong S, Dayton MR, Lyda C, Barber GR. Perioperative blood loss in total hip and knee arthroplasty: Outcomes associated with intravenous tranexamic acid use in an academic medical center. SAGE Open Med. 2016:4:2050312116637024.

25. Aletaha D, Bingham CO 3rd, Tanaka Y, Agarwal P, Kurrasch R, Tak PP, Popik S. Efficacy and safety of sirukumab in patients with active rheumatoid arthritis refractory to anti-TNF therapy (SIRROUND-T): a randomised, doubleblind, placebo-controlled, parallel-group, multinational, phase 3 study. Lancet. 2017;389(10075):1206-17

26. Kohn MD, Sassoon AA, Fernando ND. Classifications in Brief: KellgrenLawrence Classification of Osteoarthritis. Clin Orthop Relat Res. 2016;474(8): 1886-93.

27. Goodman SM, Springer B, Guyatt G, Abdel MP, Dasa V, George M, GewurzSinger O, Giles JT, Johnson B, Lee S, Mandl LA, Mont MA, Sculco P, Sporer S, Stryker L, Turgunbaev M, Brause B, Chen AF, Gililland J, Goodman M, HurleyRosenblatt A, Kirou K, Losina E, MacKenzie R, Michaud K, Mikuls T, Russell L, Sah A, Miller AS, Singh JA, Yates A. 2017 American College of Rheumatology/American Association of Hip and Knee Surgeons Guideline for the Perioperative Management of Antirheumatic Medication in Patients With Rheumatic Diseases Undergoing Elective Total Hip or Total Knee Arthroplasty. J Arthroplasty. 2017:32(9):2628-38.

28. Nadler SB, Hidalgo $\mathrm{JH}$, Bloch T. Prediction of blood volume in normal human adults. Surgery. 1962;51(2):224-32.

29. Gross JB. Estimating allowable blood loss: corrected for dilution. Anesthesiology. 1983;58(3):277-80.

30. Kathariya R. Intra-Operative Hemorrhage: A Review of Literature. J Med Diagn Methods. 2013;02(6)

31. Sehat KR, Evans RL, Newman JH. Hidden blood loss following hip and knee arthroplasty. Correct management of blood loss should take hidden loss into account. J Bone Joint Surg Br Vol. 2004;86(4):561-5.

32. Huang Z, Xie X, Li L, Huang Q, Ma J, Shen B, Kraus VB, Pei F. Intravenous and Topical Tranexamic Acid Alone Are Superior to Tourniquet Use for
Primary Total Knee Arthroplasty: A Prospective, Randomized Controlled Trial. J Bone Joint Surg Am. 2017;99(24):2053-61.

33. Dahuja A, Dahuja G, Jaswal V, Sandhu K. A prospective study on role of tranexamic acid in reducing postoperative blood loss in total knee arthroplasty and its effect on coagulation profile. J Arthroplast. 2014;29(4): 733-5.

34. Rajesparan K, Biant LC, Ahmad M, Field RE. The effect of an intravenous bolus of tranexamic acid on blood loss in total hip replacement. J Bone Joint Surg Br. 2009;91(6):776-83.

35. Hourlier H, Reina N, Fennema P. Single dose intravenous tranexamic acid as effective as continuous infusion in primary total knee arthroplasty: a randomised clinical trial. Arch Orthop Trauma Surg. 2015;135(4):465-71.

36. Jin S, Li M, Fang Y, Li Q, Liu J, Duan X, Liu Y, Wu R, Shi X, Wang Y, Jiang Z, Wang Y, Yu C, Wang Q, Tian X, Zhao Y, Zeng X. Chinese Registry of rheumatoid arthritis (CREDIT): II. prevalence and risk factors of major comorbidities in Chinese patients with rheumatoid arthritis. Arthritis Res Ther. 2017;19(1):251

37. Scott DL, Wolfe F, Huizinga TWJ. Rheumatoid arthritis. Lancet (London, England). 2010;376(9746):1094-108.

38. Skeoch S, Bruce IN. Atherosclerosis in rheumatoid arthritis: is it all about inflammation? Nat Rev Rheumatol. 2015;11(7):390-400.

39. Jimenez JJ, Iribarren JL, Lorente L, Rodriguez JM, Hernandez D, Nassar I, Perez R, Brouard M, Milena A, Martinez R, Mora ML. Tranexamic acid attenuates inflammatory response in cardiopulmonary bypass surgery through blockade of fibrinolysis: a case control study followed by a randomized double-blind controlled trial. Crit Care. 2007:11(6):R117.

40. Robson SC, Shephard EG, Kirsch RE. Fibrin degradation product D-dimer induces the synthesis and release of biologically active IL-1 beta, IL-6 and plasminogen activator inhibitors from monocytes in vitro. Br J Haematol. 1994;86(2):322-6.

41. Godier A, Roberts I, Hunt BJ. Tranexamic acid: less bleeding and less thrombosis? Crit Care. 2012;16(3):135

42. Jimenez JJ, Iribarren JL, Brouard M, Hernandez D, Palmero S, Jimenez A Lorente L, Machado P, Borreguero JM, Raya JM, Martin B, Perez R, Martinez $\mathrm{R}$, Mora ML. Safety and effectiveness of two treatment regimes with tranexamic acid to minimize inflammatory response in elective cardiopulmonary bypass patients: a randomized double-blind, dosedependent, phase IV clinical trial. J Cardiothorac Surg. 2011;6:138.

43. Mukubo $Y$, Kawamata M. Perioperative hypercoagulability in patients with rheumatoid arthritis: Sonoclot study. J Anesth. 2004;18(1):62-4.

44. Kim YH, Park JW, Kim JS, Seo DH. Does tranexamic acid increase the risk of thromboembolism after bilateral simultaneous total knee arthroplasties in Asian Population? Arch Orthop Trauma Surg. 2018;138(1):83-9.

\section{Publisher's Note}

Springer Nature remains neutral with regard to jurisdictional claims in published maps and institutional affiliations.

Ready to submit your research? Choose BMC and benefit from:

- fast, convenient online submission

- thorough peer review by experienced researchers in your field

- rapid publication on acceptance

- support for research data, including large and complex data types

- gold Open Access which fosters wider collaboration and increased citations

- maximum visibility for your research: over $100 \mathrm{M}$ website views per year

At BMC, research is always in progress.

Learn more biomedcentral.com/submissions 